\title{
Evolution of Resistance in Potamopyrgus antipodarum
}

\author{
Peyton J. Joachim, Department of Biology, Indiana University Bloomington
}

\section{ABSTRACT}

Wost-parasite interactions are believed to exert strong selection in natural communities. Most notably, 1 parasites should select for increased resistance in hosts, while hosts should select for increased infectivity in parasites (Koskella \& Lively, 2007; Koskella, Vergara, \& Lively, 2011; Lohse, Guiterrez, \& Kaltz, 2006). Under this coevolutionary process, can host populations evolve resistance to their rapidly evolving parasite populations? This experiment was designed to determine if hosts rapidly adapt to resist parasites that are themselves under selection to infect their hosts. The New Zealand freshwater snail, Potamopyrgus antipodarum, is naturally infected by the trematode Microphallus. Microphallus is a castrating parasite and is thus likely to impose strong selection on its snail host (Hechinger, 2012). Snails and parasites were collected from a natural lake in summer 2013. These hosts constitute the parental generation of the experiment: they were either exposed to parasite eggs (Exposed) or not exposed (Control). Parental snails matured and reproduced over the course of a year. Their offspring were then exposed to parasites collected from the same lake in summer 2014. These parasites would have had one to a few additional generations of evolution relative to 2013 parasites. After parasite development ( 3 months), the offspring were dissected to determine infection status and thereby their resistance to infection. The offspring of Control parents had a significantly higher mean infection rate (35\%: less resistant) than the offspring of Exposed parents (30\%: more resistant). This result indicates that increased resistance to parasitism evolved in a single host generation. Our finding provides evidence that a host population can rapidly evolve resistance to a parasite population that is itself rapidly co-evolving to infect its host. We predict that the evolution of host resistance would be far greater after multiple generations of parasite selection, and this could be the subject of future study.

KEYWORDS: resistance, parasites, adapation, host interaction, parasite development

\section{ACKNOWLEDGMENTS AND CORRESPONDENCE}

The author would like to thank Curt Lively, Amanda Gibson, Cheyenne Smith, and the rest of the Lively Lab for their support and guidance during the various phases of this research project.

All correspondence concerning this article should be addressed to Peyton J. Joachim at pejjoach@indiana.edu

\section{REFERENCES}

Hechinger R.F. (2012). Faunal survey and identification key for the trematodes (Platyhelminthes:Digenea) infecting Potamopyrgus antipodarum (Gastropoda: Hydrobiidae) as first intermediate host. Zootaxa, 3418, 1-27.

Koskella B., \& Lively, C. (2007). Advice of the rose: Experimental coevolution of a trematode parasite and its snail host. Evolution, 61(1), 152-159. doi: 10.1111/j.1558-5646.2007.00012.x

Koskella, B., Vergara D., \& Lively, C. (2011). Experimental evolution of sexual host populations in response to sterilizing parasites. Evolutionary Ecology Research, 13(3), 315-322.
Lohse K., Gutierrez, A., Kaltz, O. (2006). Experimental evolution of resistance in Paramecium Caudatum against the bacterial parasite Holospora undulate. Evolution, 60(6), 1177-1186. doi: 10.1111/j.0014-3820.2006.tb01196.x 